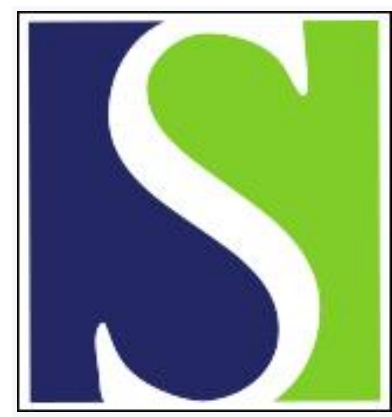

Scand J Work Environ Health 2018;44(5):530-538

https://doi.org/10.5271/sjweh.3726

Published online: 15 Mar 2018, Issue date: 01 Sep 2018

Prolonged sitting at work is associated with a favorable time course of low-back pain among blue-collar workers: a prospective study in the DPhacto cohort

by Korshøj M, Jørgensen MB, Hallman DM, Lagersted-Olsen J, Holtermann A, Gupta N

Sitting at work is suggested to increase risk for low-back pain (LBP). Thus, an association between temporal patterns of sitting and time course of LBP, across 12 months, among 665 participants from the DPhacto cohort was conducted. We found that longer durations of total and temporal sitting periods at work were significantly associated with a favorable time course of LBP.

Affiliation: National Research Centre for the Working Environment, Lersø Parkallé 105, 2100 Copenhagen, Denmark. mkl@nfa.dk

Refers to the following texts of the Journal: 2011;37(1):6-29

2016;42(2):125-134 2016;42(6):528-537 2017;43(3):269-278

Key terms: accelerometry; actigraph; blue-collar worker; DPhacto cohort; longitudinal study; low-back pain; musculoskeletal disorder; pain; physical work demand; prolonged sitting; prospective study; repeated measurement; sedentary; text message; trajectory of pain

This article in PubMed: www.ncbi.nlm.nih.gov/pubmed/29542805

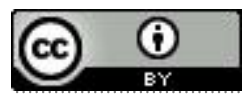




\title{
Prolonged sitting at work is associated with a favorable time course of low-back pain among blue-collar workers: a prospective study in the DPhacto cohort
}

\author{
by Mette Korshøj, PhD, ${ }^{1}$ Marie Birk Jørgensen, PhD, ${ }^{1}$ David M Hallman, PhD, ${ }^{2}$ Julie Lagersted-Olsen, PhD, ${ }^{1,3}$ Andreas \\ Holtermann, PhD, ${ }^{1,3}$ Nidhi Gupta, PhD ${ }^{1}$
}

\begin{abstract}
Korshøj M, Jørgensen MB, Hallman DM, Lagersted-Olsen J, Holtermann A, Gupta N. Prolonged sitting at work is associated with a favorable time course of low-back pain among blue-collar workers: a prospective study in the DPhacto cohort. Scand $J$ Work Environ Health. 2018:44(5):530-538. doi:10.5271/sjweh.3726
\end{abstract}

\begin{abstract}
Objective Low-back pain (LBP) is a massive health problem. Sitting at work has been suggested to be both a risk and protective factor for LBP. Thus, the objective of this study was to investigate the association between total and temporal patterns of objectively measured sitting duration and individual time course of LBP.
\end{abstract}

\begin{abstract}
Methods The analysis was performed among 665 participants from the DPhacto cohort of mainly blue-collar workers. Sitting at work was measured by accelerometry at baseline, expressed in total duration and temporal pattern [ $\%$ of working time spent in brief bursts ( $\leq 5$ minutes), moderate ( $>5-\leq 20$ minutes) and prolonged periods ( $>20$ minutes)] of sitting. Time course of LBP $(0-10$ scale $)$ were collected by monthly text messages across one year. Linear mixed models were applied to investigate the association, adjusting for potential confounders.

Results Significant negative associations between sitting duration at work and adjusted time course of LBP were found; total sitting (B -0.01, 95\% CI - $0.01--0.004$ ), brief bursts (B - $0.01,95 \%$ CI $-0.02--0.01$ ), moderate (B - $-0.01,95 \%$ CI $-0.01--0.008$ ) and prolonged periods (B - $-0.01,95 \%$ CI $-0.02--0.01$ ). Meaning, a 5 -minute increase of sitting at work will correspond to a decrease in one year time course of LBP by -0.05 points.
\end{abstract}

Conclusion Longer duration of total and temporal sitting periods at work was significantly associated with a favorable time course of LBP. This finding shows sitting at work to be beneficial for LBP, among populations of mainly blue-collar workers, by protecting from LBP aggravation.

Key terms accelerometry; actigraph; longitudinal study; musculoskeletal disorder; physical work demand; repeated measurement; sedentary; text message; trajectory of pain.

Low-back pain (LBP) is a considerable health problem with negative impact on long-term sickness absence and early retirement (1), influencing both individuals, workplaces and society (2-4). A survey from 2014 among Danish workers showed that $47 \%$ reported pain or discomfort in the back during the past 14 days (5). Hence, knowledge regarding risk factors linked to occurrence, aggravation or reduction of LBP is needed to specify and optimize prevention.

Sitting at work has been suggested to be a risk factor for LBP $(6,7)$. The reason for this may be that prolonged sitting could relate to LBP by uninterrupted, low-intensity muscle contractions, which may increase systemic levels of pro-inflammatory cytokines (8-10), as well as the loss of muscle strength due to inactivity (11). However, previous reviews, mainly using self-reported duration of sitting, have not established significant associations between duration of sitting and LBP (12-14). However, duration of sitting measured mainly by self-reports, like questionnaires, has been shown to be both biased and imprecise when compared to objective measurements (15-17). Studies using objective measures of the total and temporal patterns of sitting durations in relation to time course of LBP also

1 National Research Centre for the Working Environment, Copenhagen, Denmark.

2 Department of Occupational and Public Health Sciences, Centre for Musculoskeletal Research, University of Gävle, Gävle, Sweden.

3 Department of Sports Science and Clinical Biomechanics, University of Southern Denmark, Odense, Denmark. 
show mixed findings (17-19). These results could be explained by the cross-sectional nature of the studies $(17,19)$ or the few measurements of pain over time $(18)$. Also, the association between sitting and LBP has been investigated among different occupational groups with a variety of occupational tasks during sitting, which might affect the relation to LBP differently. Recently, a crosssectional study showed that the association between duration of sitting and intensity of LBP was moderated by body mass index (BMI) (19). Furthermore, age (20), sex (20), smoking $(21,22)$, level of occupational lifting (20), occupational sector (23), a diagnosis with a herniated disc (24), level of leisure-time physical activity (25, $26)$, intensity of physical activity and rating of perceived exertion (RPE) during working hours (27-29), previous episodes of LBP (30), and influence and social support at work $(31,32)$ have also shown associations with duration of sitting and/or intensity of LBP.

Therefore, the primary objective of this paper was to investigate the association between total and temporal patterns of objectively measured sitting duration at work and individual time course of LBP across one year. The secondary aim was to investigate whether these associations were modified by individual or work-related factors.

\section{Methods}

\section{Study design}

In brief, this prospective study is based on the Danish PHysical ACTivity cohort with Objective measurements (DPHACTO), enrolling participants from 15 companies in the cleaning, transport and manufacturing sectors between December 2011 and March 2013 (33). The data collection was conducted according to the Helsinki Declaration and approved by the Danish Data Protection Agency and local ethics committee (H-2-2012-011). All workers provided their written informed consent prior to participation.

Baseline measures included web-based questionnaires, objective measurements of anthropometrics and accelerometry. Moreover, workers were asked to state their intensity of LBP every fourth week from baseline to one-year follow-up via text messages, thus a total of 14 text messages were sent (34).

\section{Criteria for inclusion and exclusion}

Fever on the day of testing and/or pregnancy excluded workers from participating in the study, and workers with allergy to bandages or adhesives were excluded from the accelerometer measurements (33). Workers were included in the analysis if they answered $\geq 1$ of the 14 sent text messages and had valid accelerometers based measurements for $\geq 1$ working period (valid work period: duration $\geq 4$ hours/day or $\geq 75 \%$ of average wear time during work).

\section{Assessment of exposure}

Objective measurements of duration of sitting were collected using two accelerometers (ActiGraphs GT3X+, ActiGraph LLC, Pensacola, FL, USA, actigraphcorp. com), directly mounted on the skin at the front of the right thigh (at the right thigh medial between the iliac crest and the upper border of the patella) and at the back at T1-T2 level by adhesives $(17,35,36)$. If the data from the accelerometer mounted at the back did not fulfill the quality criterion, data from the hip accelerometer were used (below the upper point of the iliac crest at the right side). Sitting duration was continuously measured during 4-6 days, 24 hours a day. During these days, the participants were asked to complete a diary stating: working hours, time in bed (when they went to bed and got up in the morning), periods without wearing the monitors, and specific time of reference measurements (upright stance for 15 seconds each day). The reference measurement was used to find the transformations of coordinates between the orientation of the thigh and the axis of the accelerometer (17).

Acceleration data were sampled at a frequency of $30 \mathrm{~Hz}$ with a dynamic range of $\pm 6 \mathrm{G}$ and a 12-bit precision. The accelerometers were initialized and data was downloaded using the Actilife software (version 5.5). Accelerometer signals were low-pass filtered at $5 \mathrm{~Hz}$ using a fourth-order Butterworth filter and then split up in 2-second windows with $50 \%$ overlap, and then analyzed in the customized software called Acti4 (36). Non-wear periods were classified based on the following criteria: (i) the participant registered non-wear in the diary, (ii) the Acti4 detected periods $>90$ minutes with zero acceleration, and (iii) missing data and/or artefacts were visually detected.

Sitting posture was derived from the accelerometer at the trunk and thigh (37) and classified by a thigh inclination $>45^{\circ}$ combined with a trunk inclination $<45^{\circ}$ relative to the recorded reference position (17). The Acti4 software has shown a sensitivity of $99.9 \%$ and specificity of $100.0 \%$ for determining sitting in standardized field settings, and $98.2 \%$ and $93.3 \%$ during free living (36).

For this analysis, the duration of sitting at work was computed as total duration, as well as the temporal patterns. Total duration per day was calculated by dividing the total accumulated duration of valid periods of sitting at work across the measured workdays by the number of workdays. The temporal patterns of sitting were quanti- 
fied by the exposure variation analysis (EVA) (38). For each measurement day, the time-line from the processed accelerometer signal was divided into uninterrupted sitting periods during work. Non-sitting periods were detected as interruptions from sitting for $\geq 5$ seconds. The different EVA categories of sitting were selected from previous studies $(35,39)$, "brief bursts" (BB) (sitting periods $\leq 5$ minutes), "moderate periods" (MP) (sitting periods of $>5-20$ minutes), and "prolonged periods" (PP) (sitting periods $>20$ minutes). The mean duration (hours/ day) for each participant spent in each of the EVA categories was calculated by dividing the total accumulated duration of valid periods of sitting during work across all measured workdays by the number of workdays.

\section{Assessment of outcome}

During one year, the participants were asked to rate their intensity of LBP by answering text messages every fourth week, collected using SMS track (sms-track. com), resulting in a total of 14 text messages sent (34). The text messages asked "On a scale of $0-10$, grade the worst pain you have experienced in your lower back within the past month?" $(0=$ no pain, $10=$ worst possible pain)". Previously, the numeric rating scale has been evaluated as valid and reliable for assessment of pain (40). The time scale for the repeated measures of LBP was defined by the time since baseline.

\section{Data collection of potential confounders and moderators}

Objective measurements of body weight (Tanita BC418) and height (Seca model 123 1721009) were performed. BMI $\left(\mathrm{kg} / \mathrm{m}^{2}\right)$ was calculated from the objectively measured body weight $(\mathrm{kg})$ and height $(\mathrm{m})$. Age was based on the date of birth for the participant. Sex was determined from the question: "Are you male or female?". Smoking was assessed by the question "Do you smoke?" using four response categories, which was merged into a dichotomized variable: yes ("yes daily", "yes sometimes") and no ("used to smoke", "I have never smoked"). Time course of LBP was determined by the question: "In the last 3 months, state your worst pain in: lower back?" with an 11-point response scale from 0 ("no pain") to 10 ("worst pain imaginable") (41). Use of pain medication was determined by the question:" In the last three months, how many days have you been taking analgesics because of pain in muscles and joints?" using seven response categories, which were merged into a dichotomized variable: $0-14$ days ("0 days", "1-2 days", "3-7 days", "8-14 days") and $\geq 15$ days (" $15-30$ days", "31-60 days", "61-90 days"). A diagnosis with herniated disc was assessed by the question: "Do you have herniated discs?" with the dichotomized response "yes" or "no". Seniority in the current job (years) was assessed using the question: "For how long have you had the kind of occupation that you have now?". Four items from the Copenhagen Psychosocial Questionnaire (42) assessed influence at work (decision authority) and social support by the questions: "Do you have a large degree of influence concerning your work?"; "Can you influence the amount of work assigned to you?"; "Is there good cooperation between the management and the employees?"; "Is there good cooperation between the colleagues at work?". The 5-point response scale ranged from 1 ("always") to 5 ("never"). For the analysis, the scale was recoded to $0-100 \%$, whereby a higher score indicate a higher social support and more influence. For each of the two items, the mean was calculated. Due to a technical error in the data collection neither of the participants from the transportation sector was asked these questions regarding social support and influence at work. Occupational lifting and carrying were assessed by a single item from the Danish Work Environment Cohort Survey (DWECS): "How much of your working time do you carry or lift?" with a 6-point response scale from 1 ("never") to 6 ("almost all the time") (43), these six response categories were dichotomized into carrying or lifting $\geq 50 \%$ of the working time or carrying or lifting $<50 \%$ of the working time. Occupational group was determined by the workplace of the participant and whether the participant stated to be working in the administration (white-collar work) or in the production (blue-collar work), thereby representing four groups: cleaning, manufacturing, transportation and administration. Moderate-to-vigorous physical activity (MVPA) at leisure was assessed by accelerometer measurements, adding up leisure time spent in: running, walking in stairs, and cycling (44). The MVPA duration was normalized to the total measured leisure time. RPE was determined by the question: "How physically demanding do you normally consider your present work?" with a 10-scaled response category (1-10), where 10 was the most demanding. The following variables were tested as moderators: age, sex, BMI, occupational group, MVPA and RPE.

\section{Statistical analysis}

All statistical analyses were performed in the SAS version 9.4 (SAS Institute, Cary, NC, USA). The association between objectively measured sitting time ( $\%$ of working time, continuous variable) and time course of LBP (self-reported intensity on a $0-10$ scale across one year) was analyzed in a linear mixed-model for repeated measurements, using an autoregressive covariance structure (AR1) to adapt for the weakening of correlations due to the increased time span. Participants having missing values of intensity of LBP were not excluded from analysis. In the mixed-model analysis, the random factors were participant and intercept, and the fixed fac- 
tors were the different variables of sitting and time (14 time points across one year), their interaction, denoting an association between sitting and time course of LBP, as well as the confounders. The different variables of sitting (total sitting and brief bursts, moderate and prolonged sitting periods) were analyzed as the independent factor in separate models. The intensity of LBP and time were entered as continuous variables.

All interaction terms between sitting and the potential moderating factors (sitting $\times$ moderating factor) were included in a model to investigate whether the relation between sitting and LBP was moderated due to these factors. If the interaction was statistically significant $(\mathrm{P}<0.10)$, the interaction term was included in the final model and a complementary stratified analysis was conducted. If the potential moderating factor was not significantly moderating the association, they were considered potential confounders. The potential confounders were tested for critical multicollinearity by the variance inflation estimate; if multicollinearity was present (variance inflation factor $>5$ ), the potential confounder was not included in the adjusted model. Potential confounders were included in the adjusted model by significant $(\mathrm{P}<0.10)$ effect on the association between exposure and outcome. By default, the level of LBP the last three months from baseline and sitting during leisure time was included in the adjusted model.

Sensitivity analyses were performed to examine the robustness of the findings. One sensitivity analysis excluded those participants who stated to be free of LBP throughout all of the text measurements (answering 0 at all times). In separate sensitivity analyses, the final model was additionally adjusted for (i) influence and social support at work; (ii) use of pain medication; and (iii) selfreported changes in level of occupational physical activity across the year where the text messages were sent.

\section{Results}

\section{Flow of participants}

Figure 1 shows the flow of participants from the DPhacto included in this study. Of the 2107 employees at the enrolled companies, 665 participants were included in the analysis.

\section{Baseline characteristics of the study population}

The baseline characteristics of the study population are shown in table 1 . Among the 665 participants constituting the population included in the analysis, $439(65 \%)$ answered all 14 text messages and $576(85 \%)$ answered 12 of the 14 sent text messages.

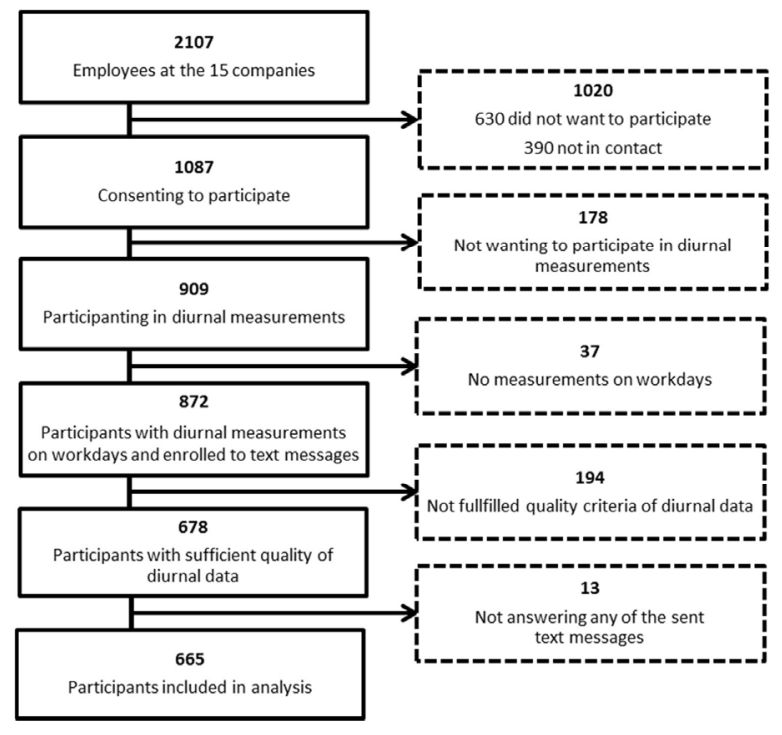

Figure 1. Flow of the participants.

\section{Construction of statistical model}

Due to the non-normal distribution of the exposure variables, a square root transformation was applied to make them fit a normal distribution. No critical multicollinearity was indicated by the multicollinearity diagnostics applied to all of the potential confounder variables, thus all of the variables were kept in the analysis.

Of the potential modifiers, time was the only variable significantly interacting with sitting on LBP across one year, in the model also adjusted for confounding factors. However, RPE $(\mathrm{P}=0.01)$ and age $(\mathrm{P}=0.05)$ were also considered as moderators due to their significant interaction with sitting duration during work in an unadjusted model. Therefore, analysis stratified on median age and RPE were applied.

The potential confounders kept in the model were diagnosis with herniated disc, peak intensity of LBP during the past three months collected at baseline, occupational lifting and sitting during leisure time.

\section{Primary analysis of association between sitting and LBP}

Table 2 shows the results from the crude and adjusted models for sitting at work (in total duration and in the temporal variables) both of which showed, significant negative associations with the time course of LBP. Back transformation, by taking the square root of the beta, shows that these negative associations corresponds to decreases in the one year time course of LBP of approximately -0.05 points, on a $0-10$ scale of LBP (corresponding change in pain in adjusted model are total time: -0.03 ; BB: -0.06; MP: -0.06; and PP: -0.06). Thus, 
Table 1. Baseline characteristics of the study population. [SD=standard deviation; LBP=low-back pain]

\begin{tabular}{|c|c|c|c|c|}
\hline & \multicolumn{4}{|c|}{ Analyzed population ( $\mathrm{N}=665$ ) } \\
\hline & Mean & SD & $\mathrm{N}$ & $\%$ \\
\hline Age (years) & 45.0 & 10.0 & & \\
\hline Sex (females) & & & 294 & 44.2 \\
\hline \multicolumn{5}{|l|}{ Sector } \\
\hline Cleaning & & & 119 & 17.9 \\
\hline Manufacturing & & & 448 & 67.4 \\
\hline Transport & & & 56 & 8.4 \\
\hline Administration & & & 42 & 6.3 \\
\hline Body mass index $\left(\mathrm{kg} / \mathrm{m}^{2}\right)$ & 27.4 & 4.9 & & \\
\hline Current smoker & & & 192 & 28.9 \\
\hline $\begin{array}{l}\text { Moderate-to-vigorous physical } \\
\text { activity during leisure (minutes) }\end{array}$ & 2.4 & 3.6 & & \\
\hline $\begin{array}{l}\text { Daily use of pain medication } \geq 15 \\
\text { days in last } 3 \text { months }\end{array}$ & & & 74 & 11.2 \\
\hline $\begin{array}{l}\text { Seniority in current occupation } \\
\text { (years) }\end{array}$ & 13.2 & 10.1 & & \\
\hline $\begin{array}{l}\text { Rating of perceived exertion (scale } \\
1-10)^{\mathrm{a}}\end{array}$ & 5.1 & 2.2 & & \\
\hline Influence at work (scale 0-100\%) & 63.6 & 25.9 & & \\
\hline $\begin{array}{l}\text { Social support at work } \\
\text { (scale 0-100\%) }\end{array}$ & 78.9 & 16.1 & & \\
\hline $\begin{array}{l}\text { Lifting and carrying at work (scale } \\
1-6)^{\mathrm{b}}\end{array}$ & 3.6 & 1.4 & & \\
\hline $\begin{array}{l}\text { Lifting and carrying at work } \geq 50 \% \\
\text { work time }\end{array}$ & & & 273 & 41.3 \\
\hline \multicolumn{5}{|l|}{ LBP - duration and intensity } \\
\hline $\begin{array}{l}\text { Average LBP in text messages } \\
\text { through } 52 \text { weeks (scale } 0-10 \text { ) }\end{array}$ & 2.3 & 2.1 & & \\
\hline $\begin{array}{l}\text { Peak LBP intensity past } 3 \text { months } \\
\text { at baseline (scale } 0-10 \text { ) }\end{array}$ & 3.4 & 3.1 & & \\
\hline LBP intensity, at baseline < 5 & & & 415 & 62.4 \\
\hline LBP intensity, at baseline $\geq 5$ & & & 247 & 37.3 \\
\hline $\begin{array}{l}\text { Days with LBP in past } 12 \text { months } \\
>30 \text { days }\end{array}$ & & & 176 & 26.5 \\
\hline \multicolumn{5}{|l|}{$\begin{array}{l}\text { Technical objective measures of } \\
\text { sitting time }\end{array}$} \\
\hline Total measured working hours & 20.0 & 8.0 & & \\
\hline Average working hours per day & 7.7 & 1.6 & & \\
\hline $\begin{array}{l}\text { Occupational sitting (\% work } \\
\text { time) }\end{array}$ & 33.6 & 22.8 & & \\
\hline $\begin{array}{l}\text { Occupational sitting in brief } \\
\text { bursts (\% work time) }\end{array}$ & 3.4 & 4.0 & & \\
\hline $\begin{array}{l}\text { Occupational sitting in moderate } \\
\text { periods (\% work time) }\end{array}$ & 6.3 & 6.1 & & \\
\hline $\begin{array}{l}\text { Occupational sitting in prolonged } \\
\text { periods ( } \% \text { work time) }\end{array}$ & 5.6 & 9.1 & & \\
\hline
\end{tabular}

a 1 ("nothing at all") to 10 ("the most demanding").

b 1 ("never") to 6 ("almost all the time").

for every $1 \%$ (corresponding to approximately five minutes) increase of sitting at work, a decrease in one year time course of -0.05 points in LBP will be expected. These results indicate that an increase in duration of sitting, independent of bout duration, would decrease the time course of LBP.

\section{Stratified analyses of association between duration of sit-} ting and time course of LBP

Adjusted analyses similar to model 2 were conducted in sub-populations stratified on age (median split of $\geq /<$ 46 years) and RPE (median split of $\geq /<6$ on scale from
Table 2. Associations for square root transformed total and temporal patterns (exposure variation analysis derivatives) of sitting during work with the time course of low-back pain (scale of 0-10 scale). Duration of sitting is reported as $10 \%$ increments of sitting time. Estimates denote the interaction sitting $\times$ time.

\begin{tabular}{|c|c|c|c|c|}
\hline & B & SE & P-value & $95 \% \mathrm{Cl}$ \\
\hline \multicolumn{5}{|c|}{ Total sitting (\% working time) } \\
\hline Model $1^{\mathrm{a}}$ & -0.050 & 0.007 & $<0.001$ & $-0.065--0.037$ \\
\hline Model ${ }^{\mathrm{b}}$ & -0.050 & 0.007 & $<0.001$ & $-0.065--0.040$ \\
\hline \multicolumn{5}{|c|}{$\begin{array}{l}\text { Brief bursts ( } \% \text { working time } \\
\text { in bouts of } \leq 5 \text { minutes) }\end{array}$} \\
\hline Model 1 & -0.124 & 0.017 & $<0.001$ & $-0.158--0.090$ \\
\hline Model 2 & -0.118 & 0.017 & $<0.001$ & $-0.152--0.084$ \\
\hline \multicolumn{5}{|c|}{$\begin{array}{l}\text { Moderate periods (\% work- } \\
\text { ing time in bouts of }>5-20 \\
\text { minutes) }\end{array}$} \\
\hline Model 1 & -0.121 & 0.017 & $<0.001$ & $-0.155--0.088$ \\
\hline Model 2 & -0.117 & 0.017 & $<0.001$ & $-0.151--0.084$ \\
\hline \multicolumn{5}{|c|}{$\begin{array}{l}\text { Prolonged periods ( } \% \text { working } \\
\text { time in bouts of }>20 \text { minutes) }\end{array}$} \\
\hline Model 1 & -0.123 & 0.018 & $<0.001$ & $-0.158--0.088$ \\
\hline Model 2 & -0.123 & 0.018 & $<0.001$ & $-0.158--0.088$ \\
\hline
\end{tabular}

$0-10)$. All of the analysis in the sub-populations of age and RPE showed results numerically and statistically similar to the results reported in table 2 on the nonstratified population (results not shown).

\section{Sensitivity analysis}

The sensitivity analysis excluding participants without any LBP throughout the study (ie, reporting 0 in pain intensity during all 14 time points, $\mathrm{N}=47$ ), showed estimates numerically and statistically similar to model 2 on the whole population (results not shown).

The sensitivity analysis additionally adjusted for influence and social support at work showed estimates numerically and statistically similar to model 2 (results not shown).

The sensitivity analysis excluding participants answering to use pain medication $>15$ days across the previous three months $(\mathrm{N}=74,11 \%)$, showed estimates numerically and statistically similar to model 2 on the whole population (results not shown).

Additionally, the analyses of associations between sitting and time course of LBP were conducted on sitting during all waking hours (leisure and work summed); the analyses showed results numerically and statistically similar to those reported in table 2 (results not shown). 


\section{Discussion}

The primary analysis showed a statistically significant interaction between sitting and time, which indicates that time significantly moderated the association between sitting and one year time course of LBP. That is, higher durations of sitting at work, both in total duration and temporal patterns, were associated with a favorable time course of LBP intensity across one year. This finding suggests that more sitting at work is a beneficial factor for LBP, which is in contrast to what a number of previous studies have suggested (8-11). However, one recent study by Lunde and colleagues (18) also found sitting at work to lower LBP prospectively. Such beneficial effect of sitting may reflect that workers are not exposed to other harmful work tasks for LBP occurring during non-sitting, and that time spent sitting may be used to recover from hazardous work tasks. For example, in this population of primarily blue-collar workers, time not spent sitting is likely allocated to other occupational activities, eg, lifting and carrying tasks, known to increase the risk for LBP (45-47).

Moreover, of the potential modifiers, only time showed to significantly interact with sitting in the adjusted model. Also age and RPE significantly interacted with sitting in the crude model, but the analysis stratified on age and RPE did not show results different from the primary analysis, indicating that age and level of RPE do not moderate the relation between sitting and time course of LBP. Although the cross sectional analysis showed a moderating effect from BMI (19) this prospective analysis did not.

Previously, a cross-sectional study in the same dataset found similar findings of the association of temporal pattern of sitting and LBP (19). Considering the results of both the cross-sectional analyses and the current prospective analyses, it seems like sitting, per se, does not impose a risk for LBP among this population of workers from primarily blue-collar sectors. These findings, of associations between sitting and LBP, is in line with some of the previous literature, using both self-reported and objective methods for retrieving information on duration of sitting $(12-14,18)$. In contrast, some crosssectional studies, using both objective and subjective methods for retrieving information on duration of sitting have reported significant positive associations between sitting and LBP $(17,48,49)$. Hence, the lack of consistency in associations between studies does not seem to be explained by the method for retrieving information on duration of sitting, and neither by low frequency or few measures of pain. Instead, the inconsistent findings on associations between sitting and LBP can be due to the great variety of study populations, eg, including a higher proportion of white- or blue-collar workers.

\section{Methodological considerations}

This study used two tri-axial accelerometers to objectively measure duration of sitting. The accelerometer data were analyzed in the Acti4 software which discriminates sitting from lying and standing and thereby minimizes the misclassification of exposure. Additionally the large size of the homogenous study population of workers is a strength due to the possibility of detection of small effect sizes with sufficient statistical power. Additionally, the sensitivity analysis showed results similar to the results in table 2 , indicating robust results.

However, some limitations are also present; the homogenous study population of blue- and white-collar workers from blue-collar sectors may limit the generalizability of the results to other populations of mainly whitecollar workers. For example, exposure to other non-sitting occupational factors being risk factors for LBP is more likely among blue- than white-collar workers. Also, the rather few white-collar workers in DPhacto limit the possibilities of comparison between white- and blue-collar occupational groups. Not all participants answered the question regarding social support and influence at work due to a technical error; therefore we are unable to completely rule out confounding by these factors. Hence, a sensitivity analysis in the sub-sample of participants answering these questions $(\mathrm{N}=464)$ was conducted with additional adjustment for social support and influence at work. This sensitivity analysis indicated our results to be robust because it showed numerical and statistical results similar to the final model in table 2 on the entire population. Another limitation is the large amount of workers with pain during baseline. Thus, it was not possible to estimate risks among initially pain-free workers. Furthermore, this study showed small associations between sitting at work and time course of LBP, implicating that future studies should take the entire exposure from body postures and physical activities into account, like in a compositional data analysis (50).

\section{Concluding remarks}

Both total and temporal patterns of sitting at work were significantly associated with a favorable time course of LBP across one year. None of the investigated moderators significantly interacted with sitting, except time. The associations indicate that sitting may be a beneficial factor for LBP by protecting from aggravation of LBP among populations of mainly blue-collar workers. However, this finding needs to be confirmed in other occupational groups. 


\section{Acknowledgements}

The authors would like to acknowledge Klaus Hansen, Dorte Ekner and Jørgen Skotte for their massive contributions in the collections and preparation of data. Also thanks to Svend Erik Mathiassen and Mette Aadahl for valuable discussions.

This study was funded by the Danish Work Environment Fund (journal number 04-2014-09 / 20140072606). The Danish Work Environment Fund didn't have any role in the study design, the collection, analysis and interpretation of the data or the writing and submission of this paper.

\section{References}

1. Lötters F, Burdorf A. Prognostic factors for duration of sickness absence due to musculoskeletal disorders. Clin J Pain 2006 Feb;22(2):212-21. http://dx.doi.org/10.1097/01. ajp.0000154047.30155.72.

2. Andersson GB. Epidemiological features of chronic lowback pain. Lancet 1999 Aug;354(9178):581-5. http://dx.doi. org/10.1016/S0140-6736(99)01312-4.

3. Hartvigsen J, Lings S, Leboeuf-Yde C, Bakketeig L. Psychosocial factors at work in relation to low back pain and consequences of low back pain; a systematic, critical review of prospective cohort studies. Occup Environ Med 2004 Jan;61(1):e2.

4. Katz JN. Lumbar disc disorders and low-back pain: socioeconomic factors and consequences. J Bone Joint Surg Am 2006 Apr;88 Suppl 2:21-4.

5. The National Health Profile. Available from: http://www. danskernessundhed.dk/ [updated 2013; cited November 15 2017].

6. Claus A, Hides J, Moseley GL, Hodges P. Sitting versus standing: does the intradiscal pressure cause disc degeneration or low back pain? J Electromyogr Kinesiol 2008 Aug;18(4):550-8. http://dx.doi.org/10.1016/j. jelekin.2006.10.011.

7. Makhsous M, Lin F, Bankard J, Hendrix RW, Hepler M, Press J. Biomechanical effects of sitting with adjustable ischial and lumbar support on occupational low back pain: evaluation of sitting load and back muscle activity. BMC Musculoskelet Disord 2009 Feb;10:17. http://dx.doi. org/10.1186/1471-2474-10-17.

8. Henson J, Yates T, Edwardson CL, Khunti K, Talbot D, Gray LJ et al. Sedentary time and markers of chronic lowgrade inflammation in a high risk population. PLoS One 2013 Oct;8(10):e78350. http://dx.doi.org/10.1371/journal. pone. 0078350 .

9. Larsen RN, Kingwell BA, Sethi P, Cerin E, Owen N, Dunstan DW. Breaking up prolonged sitting reduces resting blood pressure in overweight/obese adults. Nutr Metab Cardiovasc Dis 2014 Sep;24(9):976-82. http://dx.doi. org/10.1016/j.numecd.2014.04.011.

10. Yates T, Khunti K, Wilmot EG, Brady E, Webb D, Srinivasan B et al. Self-reported sitting time and markers of inflammation, insulin resistance, and adiposity. Am J Prev Med 2012 Jan;42(1):1-7. http://dx.doi.org/10.1016/j. amepre.2011.09.022.

11. Beach TA, Parkinson RJ, Stothart JP, Callaghan JP. Effects of prolonged sitting on the passive flexion stiffness of the in vivo lumbar spine. Spine J 2005 Mar-Apr;5(2):145-54. http://dx.doi.org/10.1016/j.spinee.2004.07.036.

12. Lis AM, Black KM, Korn H, Nordin M. Association between sitting and occupational LBP. Eur Spine J 2007 Feb;16(2):283-98. http://dx.doi.org/10.1007/s00586-0060143-7.

13. Chen SM, Liu MF, Cook J, Bass S, Lo SK. Sedentary lifestyle as a risk factor for low back pain: a systematic review. Int Arch Occup Environ Health 2009 Jul;82(7):797806. http://dx.doi.org/10.1007/s00420-009-0410-0.

14. Roffey DM, Wai EK, Bishop P, Kwon BK, Dagenais S. Causal assessment of occupational sitting and low back pain: results of a systematic review. Spine J 2010 Mar;10(3):25261. http://dx.doi.org/10.1016/j.spinee.2009.12.005.

15. Kwak L, Proper KI, Hagströmer M, Sjöström M. The repeatability and validity of questionnaires assessing occupational physical activity--a systematic review. Scand J Work Environ Health 2011 Jan;37(1):6-29. http://dx.doi. org/10.5271/sjweh.3085.

16. Lagersted-Olsen J, Korshøj M, Skotte J, Carneiro IG, Søgaard K, Holtermann A. Comparison of objectively measured and self-reported time spent sitting. Int J Sports Med 2014 Jun;35(6):534-40.

17. Gupta N, Christiansen CS, Hallman DM, Korshøj M, Carneiro IG, Holtermann A. Is objectively measured sitting time associated with low back pain? A cross-sectional investigation in the NOMAD study. PLoS One 2015 Mar;10(3):e0121159. http://dx.doi.org/10.1371/journal. pone. 0121159 .

18. Lunde LK, Koch M, Knardahl S, Veiersted KB. Associations of objectively measured sitting and standing with low-back pain intensity: a 6-month follow-up of construction and healthcare workers. Scand J Work Environ Health 2017 May;43(3):269-78. http://dx.doi.org/10.5271/sjweh.3628.

19. Korshøj M, Hallman DM, Mathiassen SE, Aadahl M, Holtermann A, Jørgensen MB. Is objectively measured sitting at work associated with low back pain? A cross sectional study in the DPhacto cohort. Scand J Work Environ Health. 2017; Epub ahead of print. https://www.ncbi.nlm.nih.gov/ pubmed/29076513.

20. Biering-Sørensen F. A prospective study of low back pain in a general population. I. Occurrence, recurrence and aetiology. Scand J Rehabil Med 1983;15(2):71-9.

21. Leboeuf-Yde C. Smoking and low back pain. A systematic literature review of 41 journal articles reporting 47 
epidemiologic studies. Spine 1999 Jul;24(14):1463-70. http://dx.doi.org/10.1097/00007632-199907150-00012.

22. Alkherayf F, Wai EK, Tsai EC, Agbi C. Daily smoking and lower back pain in adult Canadians: the Canadian Community Health Survey. J Pain Res 2010 Aug;3:155-60. http://dx.doi.org/10.2147/JPR.S11031.

23. Owen N, Sugiyama T, Eakin EE, Gardiner PA, Tremblay MS, Sallis JF. Adults' sedentary behavior determinants and interventions. Am J Prev Med 2011 Aug;41(2):189-96. http://dx.doi.org/10.1016/j.amepre.2011.05.013.

24. Chou D, Samartzis D, Bellabarba C, Patel A, Luk KD, Kisser JM et al. Degenerative magnetic resonance imaging changes in patients with chronic low back pain: a systematic review. Spine 2011 Oct;36(21 Suppl):S43-53. http://dx.doi. org/10.1097/BRS.0b013e31822ef700.

25. Heneweer H, Vanhees L, Picavet HS. Physical activity and low back pain: a U-shaped relation? Pain 2009 May;143(1):21-5. http://dx.doi.org/10.1016/j.pain.2008.12.033.

26. Rhodes RE, Mark RS, Temmel CP. Adult sedentary behavior: a systematic review. Am J Prev Med 2012 Mar;42(3):e3-28. http://dx.doi.org/10.1016/j.amepre.2011.10.020.

27. Hartvigsen J, Kyvik KO, Leboeuf-Yde C, Lings S, Bakketeig L. Ambiguous relation between physical workload and low back pain: a twin control study. Occup Environ Med 2003 Feb;60(2):109-14. http://dx.doi.org/10.1136/oem.60.2.109.

28. Jensen JN, Holtermann A, Clausen T, Mortensen OS, Carneiro IG, Andersen LL. The greatest risk for low-back pain among newly educated female health care workers; body weight or physical work load? BMC Musculoskelet Disord 2012 Jun;13:87. http://dx.doi.org/10.1186/1471-2474-13-87.

29. Borg G. Psychophysical scaling with applications in physical work and the perception of exertion. Scand J Work Environ Health 1990;16 Suppl 1:55-8. http://dx.doi. org/10.5271/sjweh. 1815 .

30. Elders LA, Burdorf A. Prevalence, incidence, and recurrence of low back pain in scaffolders during a 3-year follow-up study. Spine 2004 Mar;29(6):E101-6. http:// dx.doi.org/10.1097/01.BRS.0000115125.60331.72.

31. Villumsen M, Holtermann A, Samani A, Madeleine P, Jørgensen MB. Social support modifies association between forward bending of the trunk and low-back pain: crosssectional field study of blue-collar workers. Scand J Work Environ Health 2016 Mar;42(2):125-34. http://dx.doi. org/10.5271/sjweh.3549.

32. Lundberg U. Work conditions and back pain problems. Stress Health 2015 Feb;31(1):1-4. http://dx.doi.org/10.1002/ smi.2633.

33. Jørgensen MB, Korshøj M, Lagersted-Olsen J, Villumsen M, Mortensen OS, Skotte J et al. Physical activities at work and risk of musculoskeletal pain and its consequences: protocol for a study with objective field measures among blue-collar workers. BMC Musculoskelet Disord 2013 Jul;14:213. http://dx.doi.org/10.1186/1471-2474-14-213.

34. Lagersted-Olsen J, Thomsen BL, Holtermann A, Søgaard $\mathrm{K}$, Jørgensen MB. Does objectively measured daily duration of forward bending predict development and aggravation of low-back pain? A prospective study. Scand J Work Environ Health 2016 Jun;42(6):528-37. http://dx.doi.org/10.5271/ sjweh.3591.

35. Hallman DM, Mathiassen SE, Gupta N, Korshøj M, Holtermann A. Differences between work and leisure in temporal patterns of objectively measured physical activity among blue-collar workers. BMC Public Health 2015 Sep;15:976. http://dx.doi.org/10.1186/s12889-015-2339-4.

36. Skotte J, Korshøj M, Kristiansen J, Hanisch C, Holtermann A. Detection of physical activity types using triaxial accelerometers. J Phys Act Health 2014 Jan;11(1):76-84. http://dx.doi.org/10.1123/jpah.2011-0347.

37. Hallman DM, Gupta N, Heiden M, Mathiassen SE, Korshøj $\mathrm{M}$, Jørgensen MB et al. Is prolonged sitting at work associated with the time course of neck-shoulder pain? A prospective study in Danish blue-collar workers. BMJ Open 2016 Nov;6(11):e012689. http://dx.doi.org/10.1136/ bmjopen-2016-012689.

38. Mathiassen SE, Winkel J. Quantifying variation in physical load using exposure-vs-time data. Ergonomics 1991 Dec;34(12):1455-68. http://dx.doi. org/10.1080/00140139108964889.

39. Hallman DM, Mathiassen SE, Heiden M, Gupta N, Jørgensen MB, Holtermann A. Temporal patterns of sitting at work are associated with neck-shoulder pain in bluecollar workers: a cross-sectional analysis of accelerometer data in the DPHACTO study. Int Arch Occup Environ Health 2016 Jul;89(5):823-33. http://dx.doi.org/10.1007/ s00420-016-1123-9

40. Ferreira-Valente MA, Pais-Ribeiro JL, Jensen MP. Validity of four pain intensity rating scales. Pain 2011 Oct;152(10):2399-404. http://dx.doi.org/10.1016/j. pain.2011.07.005.

41. Kuorinka I, Jonsson B, Kilbom A, Vinterberg H, BieringSørensen F, Andersson G et al. Standardised Nordic questionnaires for the analysis of musculoskeletal symptoms. Appl Ergon 1987 Sep;18(3):233-7. http://dx.doi. org/10.1016/0003-6870(87)90010-X.

42. Pejtersen JH, Kristensen TS, Borg V, Bjørner JB. The second version of the Copenhagen Psychosocial Questionnaire. Scand J Public Health 2010 Feb;38(3_Suppl):8-24. http:/ dx.doi.org/10.1177/1403494809349858.

43. Tüchsen F, Hannerz H, Burr H, Krause N. Prolonged standing at work and hospitalisation due to varicose veins: a 12 year prospective study of the Danish population. Occup Environ Med 2005 Dec;62(12):847-50. http://dx.doi. org/10.1136/oem.2005.020537.

44. Gupta N, Heiden M, Aadahl M, Korshøj M, Jørgensen MB, Holtermann A. What Is the Effect on Obesity Indicators from Replacing Prolonged Sedentary Time with Brief Sedentary Bouts, Standing and Different Types of Physical Activity during Working Days? A Cross-Sectional AccelerometerBased Study among Blue-Collar Workers. PLoS One 2016 May;11(5):e0154935. http://dx.doi.org/10.1371/journal. pone. 0154935 . 
45. da Costa BR, Vieira ER. Risk factors for work-related musculoskeletal disorders: A systematic review of recent longitudinal studies. Am J Ind Med 2010 Mar;53(3):285323.

46. Larsson B, Søgaard K, Rosendal L. Work related neck-shoulder pain: a review on magnitude, risk factors, biochemical characteristics, clinical picture and preventive interventions. Best Pract Res Clin Rheumatol 2007 Jun;21(3):447-63. http://dx.doi.org/10.1016/j. berh.2007.02.015.

47. Coenen P, Gouttebarge V, van der Burght AS, van Dieën $\mathrm{JH}$, Frings-Dresen MH, van der Beek AJ et al. The effect of lifting during work on low back pain: a health impact assessment based on a meta-analysis. Occup Environ Med 2014 Dec;71(12):871-7. http://dx.doi.org/10.1136/ oemed-2014-102346.
48. Yue P, Liu F, Li L. Neck/shoulder pain and low back pain among school teachers in China, prevalence and risk factors. BMC Public Health 2012 Sep;12:789. http://dx.doi. org/10.1186/1471-2458-12-789.

49. Spyropoulos P, Papathanasiou G, Georgoudis G, Chronopoulos E, Koutis H, Koumoutsou F. Prevalence of low back pain in greek public office workers. Pain Physician 2007 Sep;10(5):651-9.

50. Dumuid D, Stanford TE, Martin-Fernández JA, Pedišić Ž, Maher CA, Lewis LK et al. Compositional data analysis for physical activity, sedentary time and sleep research. Stat Methods Med Res 2017 Jan;962280217710835.[Epub ahead of print]

Received for publication: 17 January 2018 